\title{
Increasing Speed and Agility of Cerebral Palsy Football Indonesian Player with UMAC-CPF Exercise Model
}

\author{
Fadilah Umar ${ }^{1, *}$, Sapta Kunta Purnama ${ }^{1}$, Mohammad Furqon Hidayatullah ${ }^{1}$, Jumintono ${ }^{2}$, \\ Yulingga Nanda Hanief ${ }^{3}$, Sri Sumarni ${ }^{4}$, Intan Suraya Ellyas ${ }^{1}$, Ulfa Fatahara Laras Fadian ${ }^{1}$ \\ ${ }^{1}$ Faculty of Sports, Sebelas Maret University, Surakarta, Central Java, Indonesia \\ ${ }^{2}$ Faculty of Technical and Vocational Education, Universiti Tun Hussein Onn Malaysia, Malaysia \\ ${ }^{3}$ Physical Education Health and Recreation, Nusantara PGRI University, Kediri, East Java, Indonesia \\ ${ }^{4}$ Faculty of Teacher Training and Education, Sebelas Maret University, Surakarta, Central Java, Indonesia
}

Received August 31, 2020; Revised October 23, 2020; Accepted November 11, 2020

\section{Cite This Paper in the following Citation Styles}

(a): [1] Fadilah Umar, Sapta Kunta Purnama, Mohammad Furqon Hidayatullah, Jumintono, Yulingga Nanda Hanief, Sri Sumarni, Intan Suraya Ellyas, Ulfa Fatahara Laras Fadian, "Increasing Speed and Agility of Cerebral Palsy Football Indonesian Player with UMAC-CPF Exercise Model," International Journal of Human Movement and Sports Sciences, Vol. 8, No. 6, pp. 329 - 336, 2020. DOI: 10.13189/saj.2020.080604.

(b): Fadilah Umar, Sapta Kunta Purnama, Mohammad Furqon Hidayatullah, Jumintono, Yulingga Nanda Hanief, Sri Sumarni, Intan Suraya Ellyas, Ulfa Fatahara Laras Fadian (2020). Increasing Speed and Agility of Cerebral Palsy Football Indonesian Player with UMAC-CPF Exercise Model. International Journal of Human Movement and Sports Sciences, 8(6), 329 - 336. DOI: 10.13189/saj.2020.080604.

Copyright $\odot 2020$ by authors, all rights reserved. Authors agree that this article remains permanently open access under the terms of the Creative Commons Attribution License 4.0 International License

\begin{abstract}
This research aims to determine the increasing speed and agility of CP Football Indonesia team players using the Umar Motor Ability Circuit-Cerebral Palsy Football (UMAC-CPF) exercise model. The research method used was pre-experimental with research design, one group pretest, and posttest design. The sample of this research was 14 all-athletes of the cerebral palsy Indonesia team. The research data were obtained using a 20 -meter sprint test instrument to measure speed and an arrowhead test to measure agility. The data's technical analysis was a t-test (hypothesis test) with a level of significance of 5\%. The influence test results using the t-test of the difference in player speed test results between pretest and posttest obtained amount t-Count 4.921 more significant than the amount t-Table 1.761 (at the level of significance 0.05), then the nil hypothesis is rejected. While the test results influence the player's agility test results between pretest and posttest obtained amount t-Count 9.169 more significant than the amount t-Table 1.761 (at the level of significance 0.05), then the nil hypothesis is rejected. Both tests mean there is an increase in the speed and agility of CP Football Indonesia players. The study concluded a significant increase in the speed and agility of the player's football team of Cerebral Palsy Indonesia using the UMAC-CPF exercise model. The research's impact makes
\end{abstract}

CP Football Indonesia team players have excellent speed and agility to improve motor skills in supporting the game.

Keywords Cerebral Palsy, Football, Speed, Agility, UMAC-CPF

\section{Introduction}

Football is a fun sports game. Many people now know and have played football. The sport is played by all people, either old or young, male or female, and people with normal or abnormal limbs (disabilities). Disability is a condition for people with limited body disorders and the severity of inactive body classification [1]. The government of a country protects individuals with disabilities and upholds their rights by enforcing disability laws [2]. Education and training providers to provide reasonable adjustments in learning programs for students with disabilities [3]. Physical education and sports activities are essential for developing and adapting to individuals with disabilities [4]. This disorder makes it problematic for those with physical disabilities, especially cerebral palsy [5]. Football Cerebral Palsy (CP) is for disability classification. Para-athletes play football for 
individuals with $\mathrm{CP}$ football with minimal impairment criteria of ataxia, hypertonia, or athetosis (i.e., the three types of disorders most commonly associated with individuals with neurological disorders [6]. Cerebral Palsy football is a team sport in which players are classified in sports classes based on the extent to which cerebral motor control disorders lead to permanent and verifiable activity restrictions that affect football skills performance [7]. Classification is an essential aspect of disability sports, especially in Paralympic sports [8].

Football cerebral palsy was formed by the Football Association, which played with some modifications [9]. Football for people with cerebral palsy plays seven versus 7 with a game time of $2 \times 30$ minutes; players must have an International Cerebral Palsy Federation Football (IFCPF) classification ranging from Grades (FT) 5 to 8 [10]. Cerebral Palsy football is a sport of the Paralympic team whose players are classified in groups according to the degree of motion control disorder due to the permanent limitations of brain disorders that affect performance activity in football skills [7].

People with cerebral palsy have been disturbed in their limbs.

Cerebral palsy is described as a permanent disorder of movement and posture followed by reduced sensory function and thinking, causing limited physical activity disorders, caused impaired damage in the brain [11]; [12]; [13]. This condition interferes with control and coordination functions. Various disorders that affect muscle strength function and motion control are the leading causes of decreased motion performance in cerebral palsy [14]. They have physical conditions with various forms of abnormalities and body movements that result in difficulty in making movements, both in the upper and lower limbs. Exceptions are found in bones, joints, muscles, nerves, and or combinations of all three. Cerebral Palsy children often experience walking with slightly stretched knees from the swing base [15]. Cerebral Palsy spastic hemiplegia children have a lack of eye coordination [16].

Some people with Cerebral Palsy are heavily involved in sports and physical activity. Such involvement is useful to consider past patterns of their involvement, contribute to confidence, be independent, and improve life quality [17]; [18]. Physical activity exercise interventions can improve motor skills in a child's endurance performance
[19]. Exercise is a planned, structured, and repetitive activity to improve fitness and interventions for people with CP [20]. Exercise can boost the overall motor ability for cerebral palsy. Motor ability is the dominant physical factor for CP footballers.

Football is a high-intensity intermittent training model in which players need to have a high physical fitness level to play successfully [21]. Components of motor capabilities such as speed, agility, strength, coordination, balance, flexibility, durability are needed by $\mathrm{CP}$ footballers to support the game. Speed and agility are essential components for the movement of CP footballers. Speed is a qualified ability in addition to strength and endurance [22]. Speed is a vital prerequisite required in football [23]. The length and frequency of steps are essential in determining the speed of sprints in football [24]. Footballers need to be speed and agility. Agility is a psychomotor skill that allows rapid change of movement direction without losing control and balance of movement [25]. Players need speed and agility to run, rotate, change direction, dribble, or face an opponent. Efforts to increase speed for children with $\mathrm{CP}$ are required [26]

Improving the speed and agility of CP Football players requires a proper training model to suit your needs. The training program must be modified for each player to optimize maximum performance in matches [27]. Many models to increase speed, but it is necessary to choose one proper exercise model for cerebral palsy. The UMAC-CPF training model (Umar Motor Ability Circuit-Cerebral Palsy Football) is one of the exercise models that can be used. Its training model develops many components of motor capability. The UMAC-CPF Training Model is a motor skills training model for $\mathrm{CP}$ footballers packed with circuit methods, with a form of motion training consisting of 32 types of flexibility exercises, eight types of strength training, eight types of balance training, eight types of exercise coordination, eight types of speed training, eight types of power exercises, eight types of agility exercises and eight types of endurance exercises [28]. This model provides many opportunities for $\mathrm{CP}$ players with limited mobility to perform various activities packed into training. Simple training is packed with circuit methods. Each component of motor capability varies the content of the exercise model. More details of the UMAC-CPF training model can be seen in figure 1 . 


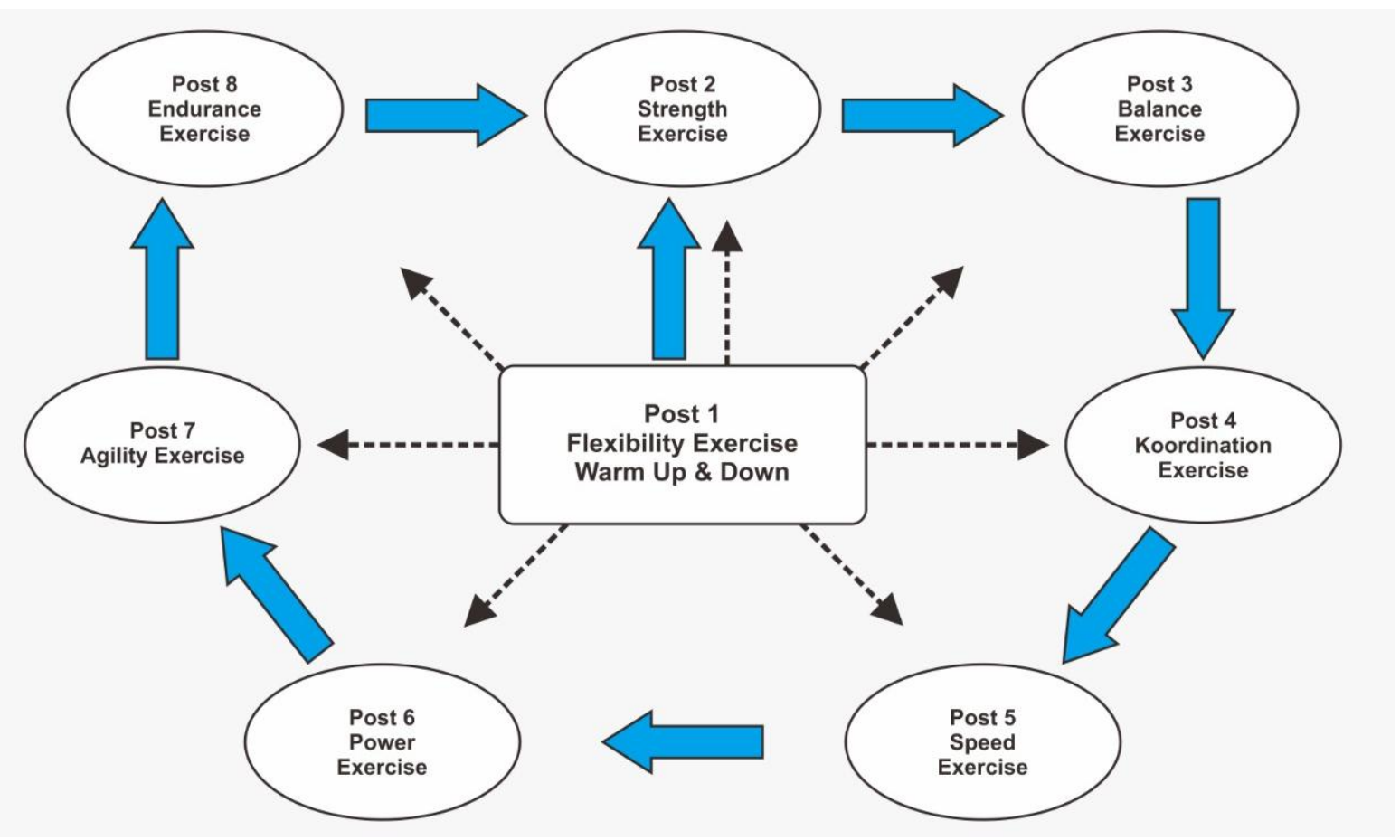

Figure 1. Training Model UMAC-CPF

Some research on CP football has been conducted, [29] in his study with the literature review model concluded that resistance training could increase muscle strength in $\mathrm{CP}$ individuals, [30] in his research tested the validity and reliability associated with sprints, acceleration/deceleration, and agility by concluding that sprint, acceleration/deceleration, and agility both with the ball and without the ball can be applied to evaluate activity restrictions from neurological disorders or take from $\mathrm{CP}$ football classes. Some other studies also analyzed jumping ability [31], endurance [32], and dribbling skills [8]. However, some of these studies have not yet conducted studies on increased speed and agility in CP football.

The UMAC-CPF speed and agility training model includes many variations. Variations of the UMAC-CPF speed training model consist of leg frequency acceleration, initial position acceleration, leg reaction acceleration, and mirror accelerated foot reaction, aerobic speed; maximum speed; anaerobic endurance speed; and football speed. Simultaneously, the agility training model's variation consists of F-Line 25m; U-Line 30m; M-cones 20m; A-Ladder 15m; R-Ladder 15m; C-Cones 25m; P-Ladder $16 \mathrm{~m}$; and F-Ladder $25 \mathrm{~m}$. Variations in existing speed and agility training models can be utilized in the exercise program.

Based on the consideration of some of these studies and some of the UMAC-CPF exercise model's uniqueness, researchers researched speed and agility using this model. This study is essential for $\mathrm{CP}$ with its many limitations that require speed and agility in supporting the performance of playing football.

\section{Objective Research}

This research aims to increase the speed and agility of CP football Indonesia team players ASEAN Para Games Philippines 2020 by using the UMAC-CPF training model. This goal is to answer the research hypothesis stating the improvement in CP Football Indonesia players' speed and capability with the UMAC-CPF training model.

\section{Materials and Methods}

This research uses quantitative research methods with pre-experimental research models. The design used in this study is On Group Pre-test - Post-test Design. This study's sample is all national cerebral palsy football Indonesia training players in 2019 , which numbered 14 people. The player classification is 2 FT1 class players, 10 FT2 players, and 2 FT3 players. The data collection tool used measurement speed capability using $20 \mathrm{~m}$ test sprint and agility capability with arrowhead for pretest and (posttest).

The research procedure was carried out through data collection of all participants by conducting a 20-meter sprint test and arrowhead agility test. Before the experiment was given, the entire sample was given an initial test with a 20-meter sprint test and an arrowhead agility test. It was then given experiments with the speed training program and the UMAC-CPF model agility training program. This training program consists of 8 models packed into 8 circuit training posts. The number of gradual training sets is given 2 - 4 circuits for eight weeks. Twenty-four trials conduct experiments on the frequency 
of exercises carried out three times a week. After doing 24 drills, she was then doing the final test with a 20-meter sprint test and arrowhead test.

Results of differences in pretest and posttest data are recorded and analyzed. The collected data is then analyzed using different testing analysis techniques or t-tests.

The player's speed and agility can be identified, improving by comparing differences in pretest results and posttest scores. The t-count calculation results are discussed with t-table at a rate of the significance of $5 \%$.

\section{Result}

\subsection{Deskripsi Pretest and Posttest}

Pretest data are data obtained before the training program is given, and posttest data are data obtained after the implementation of the training program. Score pretest results and posttest player speed and agility are presented in the following table 1.

\subsection{Normality Data}

Data normality testing is carried out before testing differences or Effectiveness. The test results normality of the initial test data and the final test of speed and agility using the Kolmogorov-Smirnov $\mathrm{Z}(\mathrm{KS}-\mathrm{Z})$ test at a significant level of $\alpha=0.05$. The KS-Z score at the pretest of 0.547 and the posttest of 0.590 mean it is more significant than $\alpha=0.05$, so the research sample is normally distributed. The results of the KS-Z agility score in the pretest were obtained 0.472 and posttest by 0.449 , which means it was also greater than $\alpha=0.05$, so the research sample on agility was distributed normally. The analysis of the normality of pretest and posttest speed and agility data is described in detail in Table 2.

Table 1. Result pretest and posttest speed and agility

\begin{tabular}{cccccccc}
\hline \multirow{2}{*}{ Respondents } & Class & \multicolumn{3}{c}{ Speed } & \multicolumn{3}{c}{ Agility } \\
\cline { 3 - 8 } & Pre-test & Post-test & Range & Pre-test & Post-test & Range \\
\hline 1 & FT 1 & 53.23 & 52.58 & -0.65 & 47.65 & 56.03 & 8.38 \\
2 & FT 1 & 41.61 & 53.55 & 11.94 & 28.24 & 50.59 & 22.35 \\
3 & FT 2 & 44.84 & 65.48 & 20.65 & 38.53 & 57.21 & 18.68 \\
4 & FT 2 & 60.65 & 70.00 & 9.35 & 31.76 & 63.09 & 31.32 \\
5 & FT 2 & 66.13 & 80.00 & 13.87 & 63.09 & 79.71 & 16.62 \\
6 & FT 1 & 51.61 & 46.45 & -5.16 & 18.971 & 47.21 & 28.24 \\
7 & FT 2 & 65.16 & 71.29 & 6.13 & 57.06 & 72.50 & 15.44 \\
8 & FT 2 & 52.26 & 70.00 & 17.74 & 44.71 & 58.53 & 13.82 \\
9 & FT 2 & 58.71 & 60.32 & 1.61 & 34.12 & 48.53 & 14.41 \\
10 & FT 2 & 48.71 & 66.45 & 17.74 & 47.06 & 65.59 & 18.53 \\
11 & FT 2 & 38.39 & 53.23 & 14.84 & 27.79 & 49.71 & 21.91 \\
12 & FT 2 & 50.32 & 59.68 & 9.35 & 18.68 & 29.12 & 10.44 \\
13 & FT 3 & 60.65 & 69.35 & 8.71 & 56.32 & 79.12 & 22.79 \\
14 & FT 3 & 50.32 & 65.16 & 14.84 & 33.24 & 68.38 & 35.15 \\
\hline & Average & 53.041 & 63.111 & 10.069 & 39.086 & 58.950 & 19.863 \\
& Sd & 8.389 & 9.216 & 7.492 & 13.989 & 13.798 & 7.716
\end{tabular}

Table 2. Results of pretest and posttest normality calculation

\begin{tabular}{cccccc}
\hline \multirow{2}{*}{ Statistik } & \multicolumn{2}{c}{ Speed } & \multicolumn{2}{c}{ Agility } & Description \\
\cline { 2 - 5 } & Pretest & Posttest & Pretest & Posttest & \\
$\mathrm{N}$ & 14 & 14 & 14 & 14 & normal \\
Kolmogorov-Smirnov Z & .547 & .590 & .472 & .449 & normal \\
Asymp. Sig. (2-tailed) & .926 & .877 & .979 & .988 & \\
\hline
\end{tabular}


Based on table descriptions and previous explanations, it was concluded that all speed data and agility data came from normally distributed samples. This conclusion provides implications that parametric statistical analysis can be used to test the influence of the models proposed in this study so that the first requirements for testing of model influence tests have been met.

\subsection{Exercise Effectiveness}

After normality testing of the pretest results and posttest speed and agility, the effectiveness test is then carried out using the "t-test." Effectiveness testing is carried out using the initial test difference test and the final test. The difference between the average pretest and posttest to determine is the increase in speed and agility after being given the exercise program.

The results speed test difference obtained an at-count of 4.921 more significant than the amount of t-table $=1.761$ (at a rate of the significance of 0.05 ); hence the nil hypothesis was rejected. It can be concluded that there is a significant difference between the player's pretest and posttest speed. Of the average pretest results of 53.041 and posttest 63.041 were processed, the difference in the increase was 10.069 or $18.98 \%$.

While the test results of the agility test difference resulted in an at-count of 9.169 more significant than the number of t_tabel 1.761 (at a level of significance of 0.05), the nil hypothesis was rejected. It can be concluded that there is a significant difference between the pretest and posttest agility of CP Football Indonesia Team Players ASEAN Para games in the Philippines. Of the average pretest results of 38.666 and posttest 58.950 , the difference in value increased by 20.284 or $52.46 \%$. A brief explanation of the different tests and the magnitude of the increase in speed and agility tests can be seen in table 3 .

\section{Discussion}

This research aims to increase the Indonesia Football Cerebral Palsy Team players' speed and agility capabilities using the UMAC-CPF training model. Study subjects were treated 24 times with speed training models and UMAC-CPF agility exercise models. The results showed that the player's speed and agility abilities were improved over the past eight weeks. They have increased player speed capability by $18.98 \%$ and agility by $52.46 \%$.

Football for people with cerebral palsy is contested seven versus seven players with a game time of $2 \times 30$ minutes; players must have an International Cerebral Palsy Federation Football (IFCPF) classification ranging from Grades (FT) 5 to 8 [10]. The rules of the player category in CP Football before 2018 are divided into four classes. Player classes are FT5, FT6, FT7, and FT 8. The latest changes are for ft5 and FT6 class player groups to incorporate FT1 class, FT7 class players into categories for FT2, and FT8 class players into FT3 classes. The new classification profile's implementation came into effect on January 8, 2018, while the previous classification rules use the 2015 regulations in classification rules [33]. The grouping category is based on the level of a player's motor ability determined by the Classifier. IFCPF places Classifiers in specific competitions as mandatory officials of each match [33].

Football performance depends on several aspects, such as technical, tactical, psychological, physical, and physiological factors [34]; [9]; [13]. Footballers must have good physical performance. They must have an excellent ability to run, jump, sprint, crouch, change direction, and rhythm [35]. They must have an excellent ability to run, jump, sprint, crouch, change direction, and rhythm. Players must effectively move to utilize strength, speed, power, agility, balance, flexibility, and endurance [36]. The ability of players to control speed is essential for the gait of various activities [26]. Speed has different characteristics in each other movement [22]. Footballers are asked to turn around, run, and change pace during matches [37]; it takes speed to hit an opponent who is mastering the ball [38]. During a football game, players change direction every 2 to 4 seconds [39].

Cerebral Palsy football players have some motoric control disorders that limit their activity and performance in football [7]; the matches are played with some modifications [9], so the conditions are different from conventional football. Recent research by [40] explains that footballers with $\mathrm{CP}$ travel less distance on high-intensity runs and sprints, perform several close-range accelerations and moderate and high-intensity decelerations, have lower player loads, and make fewer changes of direction in official matches as opposed to conventional football players as reported in other studies. That is, CP footballers require speed and agility.

The implementation of UMAC-CPF training in this study succeeded in improving Indonesian Cerebral Palsy football players' agility. Athletes with dystonia, athetosis, and ataxia, in particular, usually have problems with balance and start, stop and spin while running [30], so UMAC-CPF training is one of the right forms of exercise to improve directional ability (agility).

Table 3. Results of the signification of the exercise model

\begin{tabular}{cccccccc}
\hline Test & Pretest & Posttest & t-Count & t-Table & Description & Range & $\%$ \\
\hline Speed & 53.041 & 63.111 & 4.921 & 1.761 & Significant & 10.069 & 18.98 \\
Agility & 38.666 & 58.950 & 9.169 & 1.761 & Significant & 20.284 & 52.46 \\
\hline
\end{tabular}


Some studies that seek to improve speed and agility skills in football players with $\mathrm{CP}$ do not yet exist, but some studies on speed or agility in football players with CP are already underway. One of them is a study conducted by [30], which aims to test the validity and reliability of change of directions ability (CODA) with Modified Agility Test (MAT) and Illinois Agility Test (IAT). IAT and MAT can be useful, reliable, and valid tests for analyzing the performance of direction/agility (CODA) capabilities in football players with $\mathrm{CP}$, as activity limitations in test performance have been shown compared to controls. Later [41] in his study successfully compared the physical needs of regular football players and football players with CP. The physical demands of footballers with $\mathrm{CP}$ are lower than that of regular football players.

These findings confirm that increased speed and agility capabilities are not limited to familiar players or athletes, but in football players with $\mathrm{CP}$ can also be improved. Also, the UMAC-FC training model tends to be precisely used for the increased speed and agility capabilities of CP football players. These findings confirm that increased speed and agility capabilities are not limited to familiar players or athletes, but in football players with $\mathrm{CP}$ can also be improved. Besides, the UMAC-FC training model tends to be precisely used for $\mathrm{CP}$ football players' increased speed and agility capabilities.

In conducting the research, some limitations include experiments conducted limited to aspects of speed and agility only, no control group research methods, and no grouping player abilities based on classification. Further research can be done on other aspects of motor ability, such as flexibility, balance, strength, power, endurance, and study with the control group.

\section{Conclusions}

The study concluded a significant increase in the speed dan agility of the player's football team of Cerebral Palsy Indonesia using the UMAC-CPF exercise model. They have increased d player speed capability by $18.98 \%$ and agility by $52.46 \%$. The research implications result in making players of the CP Football Indonesia team have an excellent speed to improve the motor ability to support the game. The UMAC-CPF training model can be used as a guideline and further research for coaches, players, contractors, therapists, stakeholders, researchers, and anyone who develops motor skills for cerebral palsy.

\section{Acknowledgments}

The Author thanked the Rector, Head of Research and Community Service Institutes, Dean of the Faculty of Sport, Head of the Sports Training Education Department, all the academic civitas of the University of Sebelas Maret, National Paralympic Committee of Indonesia, and the entire Indonesia CP Football team for support and assistance in this study.

\section{REFERENCES}

[1] D. Pastor, M. Campayo-Piernas, J. T. Pastor, and R. Reina, "A mathematical model for decision-making in the classification of para-footballers with different severity of coordination impairments," J. Sports Sci., vol. 37, no. 12, pp. 1403-1410, 2019, DOI: 10.1080/02640414.2018.1560617.

[2] K. H. Alshamri, "Challenges and experiences of high school teachers with students having intellectual disabilities in inclusive classrooms in Saudi Arabia," Univers. J. Educ. Res., vol. 8, no. 5, pp. 2191-2196, 2020, DOI: 10.13189/ujer.2020.080559.

[3] J. Du Plessis and B. Ewing, "Reasonable Adjustments in Learning Programs: Teaching Length, Mass and Capacity to Students with Intellectual Disability," Univers. J. Educ. Res., vol. 5, no. 10, pp. 1795-1805, 2017, DOI: 10.13189/ujer.2017.051018.

[4] S. Aslan, "Examination of parental and special education teachers' attitudes towards sports activities of students with intellectual disability," Univers. J. Educ. Res., vol. 6, no. 11, pp. 2691-2695, 2018, DOI: 10.13189/ujer.2018.061136.

[5] J. P. Winnick and F. X. Short, Brockport physical fitness test manual: a health-related assessment for youngsters with disabilities. 2014.

[6] L. F. Daniel, R. Reina, J. I. Gorla, T. Bastos, and A. Roldan, "Validity and reliability of a test battery to assess the change of directions with the ball dribbling in para-footballers with cerebral palsy," Brain Sci., vol. 10, no. 2, pp. 1-11, 2020, DOI: 10.3390/brainsci10020074.

[7] R. Reina, A. Iturricastillo, D. Castillo, T. Urbán, and J. Yanci, "Activity limitation and match load in para-footballers with cerebral palsy: An approach for evidence-based classification," Scand. J. Med. Sci. Sport., vol. 30, no. 3, pp. 496-504, 2020, DOI: 10.1111/sms.13583.

[8] R. Reina, A. Iturricastillo, R. Sabido, M. C. Piernas, and J. Yanci, "Vertical and Horizontal Jump Capacity in International Cerebral Palsy Football Players," Int. J. Sports Physiol. Perform., 2017.

[9] C. Boyd, C. Barnes, S. J. Eaves, C. I. Morse, N. Roach, and A. G. Williams, "A time-motion analysis of Paralympic football for athletes with cerebral palsy," Int. J. Sport. Sci. Coach., vol. 11, no. 4, pp. 552-558, 2016, DOI: $10.1177 / 1747954116654786$.

[10] J. Yanci et al., "Muscle strength and anaerobic performance in football players with cerebral palsy," Disabil. Health J., vol. 9, no. 2, pp. 313-319, 2016, DOI: 10.1016/j.dhjo.2015.11.003.

[11] S. A. Rethlefsen, D. D. Ryan, and R. M. Kay, "Classification systems in cerebral palsy," Orthop. Clin. North Am., vol. 41, no. 4, pp. 457-467, 2010, DOI: 10.1016/j.ocl.2010.06.005.

[12] N. Chrysagis, E. K. Skordilis, N. Stavrou, E. Grammatopoulou, and D. Koutsouki, "The effect of treadmill training on gross motor function and walking 
speed in ambulatory adolescents with cerebral palsy: A randomized controlled trial," Am. J. Phys. Med. Rehabil., vol. 91, no. 9, pp. 747-760, 2012, DOI: 10.1097/PHM.0b013e3182643eba.

[13] A. Kakooza-Mwesige, C. Andrews, S. Peterson, F. W. Mangen, A. C. Eliasson, and H. Forssberg, "Prevalence of cerebral palsy in Uganda: a population-based study," Lancet Glob. Heal., vol. 5, no. 12, pp. e1275-e1282, 2017, DOI: 10.1016/S2214-109X(17)30374-1.

[14] S. W. Blundell, R. B. Shepherd, C. M. Dean, R. D. Adams, and B. M. Cahill, "Functional strength training in cerebral palsy: A pilot study of a group circuit training class for children aged 4-8 years," Clin. Rehabil., vol. 17, no. 1, pp. 48-57, 2003, DOI: 10.1191/0269215503cr584oa.

[15] M. M. van der Krogt, C. A. M. Doorenbosch, and J. Harlaar, "The effect of walking speed on hamstrings length and lengthening velocity in children with spastic cerebral palsy," Gait Posture, vol. 29, no. 4, pp. 640-644, 2009, DOI: 10.1016/j.gaitpost.2009.01.007.

[16] W. L. Wu, R. Alsakhawi, and S. ElKholi, "Effects of audiovisual feedback on eye-hand coordination in children with cerebral palsy," Res. Dev. Disabil., vol. 101, no. February 2019, p. 103635, 2020, DOI: 10.1016/j.ridd.2020.103635.

[17] C. J. Gaskin, M. B. Andersen, and T. Morris, "Sport and physical activity in the life of a man with cerebral palsy: Compensation for disability with psychosocial benefits and costs," Psychol. Sports Exerc., vol. 11, no. 3, pp. 197-205, 2010, DOI: 10.1016/j.psychsport.2009.12.003.

[18] S. M. Mensch, M. A. Echteld, R. Lemmens, A. Oppewal, H. M. Evenhuis, and E. A. A. Rameckers, "The relationship between motor abilities and quality of life in children with severe multiple disabilities," J. Intellect. Disabil. Res., vol. 63, no. 2, pp. 100-112, 2019, DOI: 10.1111/jir.12546.

[19] S. Kobel, L. Henle, C. Laemmle, O. Wartha, B. Szagun, and J. M. Steinacker, "Intervention Effects of a Kindergarten-Based Health Promotion Programme on Motor Abilities in Early Childhood," Front. Public Heal., vol. 8, no. June, pp. 1-9, 2020, DOI: 10.3389/fpubh.2020.00219.

[20] R. JM, C. EE, N. SG, and O. C. NE, "Exercise interventions for cerebral palsy (Review)," Cochrane Database Syst. Rev., no. 6, pp. 1-159, 2017, doi: 10.1002/14651858.CD011660. pub2.www.cochranelibrary.com.

[21] D. Albano, S. Coppola, and R. Vastola, "Vertical jump performance in Italian elite Trials athletes Vertical jump performance in Italian elite Trials athletes," no. November 2019, 2020, DOI: 10.7752/jpes.2019.s6316.

[22] Z. Radák, "Speed as a Complex Conditional Ability," Physiol. Phys. Train., pp. 111-118, 2018, DOI: 10.1016/b978-0-12-815137-2.00006-1.

[23] S. Altmann, S. Ringhof, R. Neumann, A. Woll, and M. C. Rumpf, Validity and reliability of speed tests used in soccer: A systematic review, vol. 14, no. 8. 2019.

[24] A. Miyamoto, H. Maehana, and T. Yanagiya, "The relationship between sprint speed and sprint motion in amputee soccer players," Eur. J. Adapt. Phys. Act., vol. 12, no. 2, pp. 1-9, 2019, DOI: 10.5507/euj.2019.009.
[25] S. Sermaxhaj, F. Arifi, and A. Bahtiri, "The effect of static stretching in agility and isokinetic force at football players," Sport Mont, vol. 15, no. 3, pp. 29-33, 2017, DOI: 10.26773/smj.2017.10.005.

[26] J. R. Davids, N. Q. Cung, S. Chen, M. Sison-Williamson, and A. M. Bagley, "Control of Walking Speed in Children with Cerebral Palsy," J. Pediatr. Orthop., vol. 00, no. 00, 2017, DOI: 10.1097/BPO.0000000000000978.

[27] T. Modric, S. Versic, and D. Sekulic, "Playing position specifics of associations between running performance during the training and match in male soccer players," Acta Gymnica, 2020, DOI: 10.5507/ag.2020.006.

[28] F. Umar, J. Tangkudung, and M. Asmawi, "the Developments of Motor Ability Exercise Models for Cerebral Palsy Football Players With Circuit Method," Eur. J. Phys. Educ. Sport Sci., vol. 3, no. 7, pp. 91-102, 2017, DOI: 10.5281 /zenodo. 822480

[29] J. R. M. Fleeton, R. H. Sanders, and C. Fornusek, "Strength Training to Improve Performance in Athletes With Cerebral Palsy: A Systematic Review of Current Evidence," $J$. Strength Cond. Res., vol. 34, no. 6, pp. 1774-1789, 2020, DOI: $10.1519 /$ JSC.0000000000003232.

[30] R. Reina, J. M. Sarabia, J. Yanci, M. P. García-Vaquero, and M. Campayo-Piernas, "Change of direction ability performance in cerebral palsy football players according to functional profiles," Front. Physiol., vol. 6, no. JAN, pp. 18, 2016, DOI: 10.3389/fphys.2015.00409.

[31] J. Cámara, I. Grande, G. Mejuto, A. Los Arcos, and J. Yanci, "Jump landing characteristics in elite soccer players with cerebral palsy," Biol. Sport, vol. 30, no. 2, pp. 91-95, 2013, DOI: $10.5604 / 20831862.1044223$.

[32] S. Kloyiam, S. Breen, P. Jakeman, J. Conway, and Y. Hutzler, "Soccer-specific endurance and running economy in soccer players with cerebral palsy," Adapt. Phys. Act. Q., vol. 28, no. 4, pp. 354-367, 2011, DOI: 10.1123/apaq.28.4.354

[33] I. F. of C. P. F. IFCPF, IFCPF Classification Rules 2018, no. January. 2018.

[34] J. Ade, J. Fitzpatrick, P. S. Bradley, J. Ade, J. Fitzpatrick, and P. S. B. High-intensity "High-intensity efforts in elite soccer matches and associated movement patterns, technical skills and tactical actions. Information for position-specific training drills," vol. 0414, no. August 2016, DOI: 10.1080/02640414.2016.1217343.

[35] S. Anastasiadis, A. Anogeianaki, G. Anogianakis, D. Koutsonikolas, and P. Koutsonikola, "Real-time estimation of physical activity and physiological performance reserves of players during a game of soccer," Natl. Libr. Med., pp. 13-15, 2004, DOI: 10.3233/978-1-60750-942-4-13.

[36] M. Portas, C. Rush, C. Barnes, and A. Batterham, "Method comparison of linear distance and velocity measurements with global positioning satellite (GPS) and the timing gate techniques," J. Sport. Sci. Med., pp. 6-11, 2007.

[37] T. O. Stolen, K. Chamari, S. M. Hospital, C. Castagna, and U. Wisloff, "Physiology of Soccer," no. February 2005, DOI: 10.2165/00007256-200535060-00004. 
[38] R. Bahtra, M. Asmawi, Widiastuti, and F. Dlis, "Improved vo2max: The effectiveness of basic soccer training at a young age," Int. J. Hum. Mov. Sport. Sci., vol. 8, no. 3, pp. 97-102, 2020, DOI: 10.13189/saj.2020.080304.

[39] K. Davids, A. Lees, and L. Burwitz, "Understanding and measuring coordination and control in kicking skills in soccer: implications for talent identification and skill acquisition. / Comprehension et Mesure de la coordination et du controle lors de la frappe Avec le pied en football: implica," J. Sports Sci., vol. 18, no. 9, pp. 703-714, 2000, [Online]. Available: http://articles.sirc.ca/search.cfm?id=S660571\%5Cnhttp://search.ebscohost.com/login.aspx?direct
$=$ true $\& \mathrm{db}=\mathrm{s} 3 \mathrm{~h} \& \mathrm{AN}=$ SPHS- $660571 \&$ site $=$ ehost-live $\% 5 \mathrm{Cnh}$ ttp:

[40] J. Yanci, D. Castillo, A. Iturricastillo, and R. Reina, "Evaluation of the official match external load in soccer players with cerebral palsy," J. Strength Cond. Res., vol. 33, no. 3, pp. 866-873, 2019, DOI: $10.1519 /$ jsc.0000000000002 085 .

[41] M. Henriquez, S. Riquelme, M. Abarca, F. Morales, and R. Reina, "The Journal of Sports Medicine and Physical Fitness 2020 May 20," J. Sport. Med. Phys. Fit. 2020 May 20, p. 23736, 2020, DOI: 10.23736/S0022-4707.20.10514-0. 